\title{
Death and Digital Photography
}

\section{HELEN ENNIS}

AUSTRALIAN NATIONAL UNIVERSITY

Death as we know it cannot be our death, but is always instead the deaths of others. ${ }^{1}$

This essay will consider the new possibilities for the representation of dying and death in Australia that have been enabled by the now widespread use of digital photography and the internet. Evidence suggests that photographing the dying and dead in Australia, practiced in the second half of the nineteenth century, did not reemerge on a significant scale until the 1980s. In the last ten years, digital photography and the internet have ushered in a new era, giving their users unprecedented degrees of control and privacy. Here, I provide some historical context for these developments, showing how photography has been intimately involved with the representation of death since its earliest applications in Australia.

I first began to seriously consider vernacular photographs of dying and death in 2006 while researching the exhibition Reveries: Photography and Mortality, which I curated for the National Portrait Gallery, Canberra. ${ }^{2}$ Reveries was principally 
concerned with photography that related either to one's own death or the death of another person (usually closely connected to the photographer). It comprised photographs from the 1980s up to the present by professional, mostly art-trained, photographers from Australia and New Zealand. The work, though intensely personal in nature, could be situated within a gallery context; it was produced within the familiar conventions of art photography and public display. The photographs were often large in scale, sometimes life size; they were more likely to be in black and white than colour; were presented in series and extended narratives, and were frequently accompanied by artists' contextual statements. The artists involved had significant careers and in a number of cases had previously exhibited or published the work selected for the exhibition-though it was generally not in a context concerned with mortality.

My original intention with Reveries had been to bring together different kinds of photography to juxtapose professional and non-professional (that is, vernacular) photographs and to create a dialogue between what could be crudely described as the public and private. I abandoned the idea because the images and objects from the two areas were of such a different order. With their focus on individual experience, vernacular photographs were too specific-and sometimes too emotionally raw - to be presented alongside the highly mediated and selfconscious art works in the exhibition. This, together with their inherent modesty and artlessness, meant that the vernacular photographs begged for consideration on their own terms.

It also became obvious around this time that a dramatic transition was occurring as photography moved from analogue to digital. Earlier vernacular photographs, from the late 1980s till around 2005, were in the form of coloured snapshots, generally taken on instamatic cameras and processed commercially. But, as my research for Reveries became more widely known, friends, colleagues and strangers alike began to show me post-mortem photographs that had been produced with digital technologies. While digital technology involving the use of digital cameras and mobile phones was clearly influencing the production of images, it was having other broader effects as well. Particularly significant were the emerging changes to material form. In contrast to nineteenth-century post-mortem photography and the great majority of analogue vernacular photography, many 
digital images are never printed. They never assume a tangible, physical form and exist only as digital files, part of increasingly vast digital archives held by individuals. I have had the curious experience of being shown extraordinarily intimate photographs of a loved one's last moments on the screens of mobile phones, laptops and desktop computers. Another key change inaugurated by digital technologies and the internet was the means of distributing images, especially in cases where email is used.

Analogue and digital photography associated with dying and death has much in common, especially the dominance of portraiture, a strong, direct connection between subject and photographer, and an informal, snapshot quality. But digital technologies are providing new imaging possibilities as well as new social and cultural possibilities. It seems probable to me that these technologies are contributing to an increase in the volume of death-related vernacular imagery, including post-mortem portraiture.

A consideration of vernacular digital photographs of death is immediately vexed. First, I cannot find them myself; I cannot come across them by chance. I can only be shown them or told about them by those who know of my research and my interest. This is usually individuals, who speak of their experiences in the first person, who know death intimately through the loss of a loved one-a baby, a partner, a member of their family. Second, having seen the images, I cannot show them to you. You can only take my word for them (though you may have taken some yourself or seen them within your own inner circle). How is it possible then to speak of photographs that are invisible and that for the most part will remain so? Is speaking of them any less a violation of their privacy and what can be seen as their vulnerability?

And then there is the question of context. How might vernacular digital photographs relate to representations of the dying and dead, to photographic history and contemporary practice? Unlike art works dealing with the subject, the production of these photographs is neither theorised nor historicised. There are no publications on Australian post-mortem photographs with which people can familiarise themselves and very little general knowledge on the subject. Finally, what bearing does vernacular photography of death have on contemporary issues about privacy and secrecy, and on ideas about community and the social? 
There is nothing new about the desire to depict the dying and dead. Death masks, paintings and drawings of the dead make regular appearances in Western art history. To take just a few examples: Monet's painting of Camille Monet on her deathbed, 1879; Ferdinand Hodler's series of paintings of his dying lover, Valentine Godé-Darel, 1915; in Australia, Maximillian Ludwig Kreitmayer's death mask of the bushranger Ned Kelly. Following the invention of photography, post-mortem portraits were produced in the full range of techniques, from the daguerreotypes and ambrotypes of the 1840s, '50s and '60s to albumen prints from the 1860s until the 1890s. As photography's reach expanded during the nineteenth century even the smallest towns and settlements in the United States, Great Britain, Europe and Australia had their own photographers, or access to photography through the visits of travelling photographers.

Because scholarship on nineteenth-century post-mortem portraiture is a relatively recent phenomenon, it is not yet clear how widespread photographs of the dead were. Were they universal in Western societies? Or did ethnic background, religious beliefs and different cultural factors govern their production? Research on the subject has been most intense in the United States, in part because of the existence of an active collectors' market for photographs. Exhibitions and publications have been devoted to post-mortem portraiture, with Jay Ruby's book Secure the Shadow: Death and Photography in America being particularly influential. ${ }^{3}$

In Australia, it was long assumed that photographing the dead was not part of an Australian cultural practice or tradition. ${ }^{4}$ Now, evidence is proving otherwise. At the same time that contemporary vernacular post-mortem portraiture appears to be increasing, so is historical research into the practice. Against the backdrop of changing attitudes to death, new historical material is coming to light and previously unknown images from public collections around the country are being widely disseminated via the internet. Nineteenth-century post-mortem portraits are now easily accessible in the public domain, for example, through Picture Australia. ${ }^{5}$

Evidence that the dead were photographed in the nineteenth century is not confined to the visual. In 1858 French photographer Antoine Fauchery, who worked briefly in Melbourne, advertised his services as follows:

Mr Antoine Fauchery is ready to take portraits, landscapes, and views of public buildings or private residences, in large sizes, by quite a new 
process; and also to operate the reproduction of Portraits, Engravings, or

Pictures into as many copies as desired. Likenesses taken after death. ${ }^{6}$

Even without photographers explicitly advertising 'likenesses after death', the informal exchange of information in colonial society would have enabled clients to understand that this service could be called on when required.

Such visual material is held in libraries across the country and, no doubt, in yet-to-be catalogued and digitised holdings of historical societies as well. Postmortem portraits are included in one of the best-known nineteenth-century photographic archives, the Holtermann Collection in the Mitchell Library, State Library of New South Wales, which consists of work undertaken by the American and Australasian Photographic Company (A\&A) between 1872 and 1874. A\&A's photographers, Beaufoy Merlin and Charles Bayliss, photographed hundreds of residents in regional areas of New South Wales and Victoria, most famously at the goldfields towns of Hill End and Gulgong. Two of their post-mortem photographs are of babies-one lying in a coffin, the other lying across what appears to be an adult's knees draped in fabric; a third depicts a woman laid out before being placed in a coffin. As is common, there is little identification: only one subject is named and then only in general terms as the child of the Simpson family. Two decades later the Broken Hill studio Patterson and Prestwich made a post-mortem photograph of a now-unidentified young boy (National Library of Australia collection). It is more polished than its earlier counterparts, vignetted and soft-toned, with the boy dressed in white and enclosed in a white, fabric-lined coffin.

These portraits are typical of their time. In contrast to now, the deceased in the late nineteenth century were photographed by professional photographers, either at the grieving family's home where the body was laid out prior to the funeral, or at the photographer's studio. Portraiture of any kind was a formal affair and postmortem portraiture displayed the maximum degree of preparation and deliberation. The deceased were dressed in their best clothes, with babies presented in their christening gowns and sometimes bonnets. Flowers were often arranged around the body but were generally the only form of adornment. Photographers took great care 


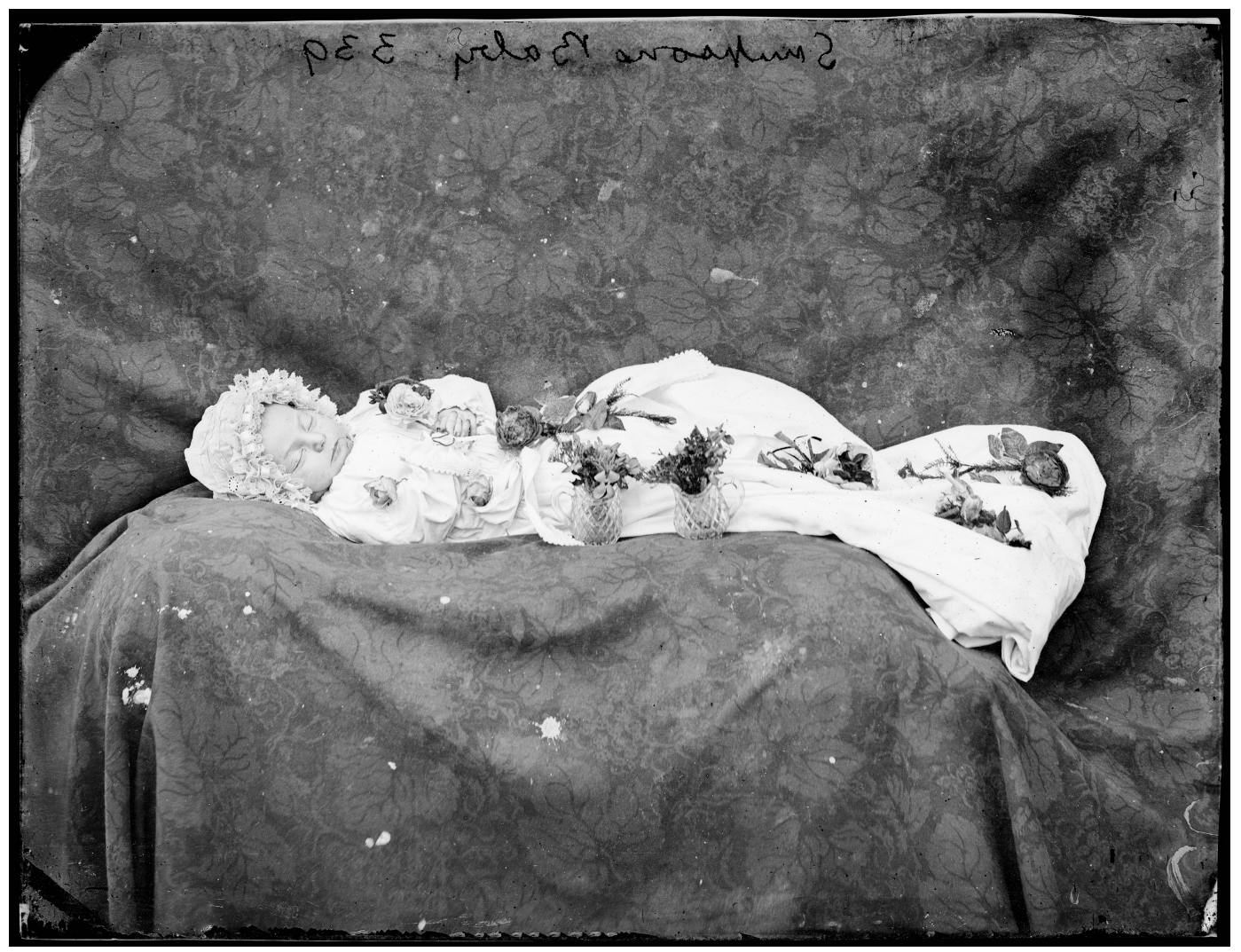

American \& Australasian Photographic Company, Corpse of Simpson's baby on the knees of the mother or father (?) hidden behind a cloth, 1870-1875, glass photonegative; quarter plate (Source: Mitchell Library, State Library of NSW Call number, Home and Away - 40916)

with their compositions and chose vantage points that kept them a respectful distance from the dead subject. In photographs of babies the entire body is usually included in the frame, but in the case of adults and children alike it is the face that is most important. Use of metaphor and idealisation is apparent, with the conflation of death and sleep creating ambiguity in some images (the subject's eyes are usually closed). In Australia, as in the United States, dead children were frequently represented as 'sleeping beauties'. Family members were usually excluded from the photograph, the focus being on the depiction of the individual. The relational would be enacted later, with the incorporation of the post-mortem portrait into family life.

For the Victorians, who had to deal with high rates of mortality (especially in children who succumbed to diseases such as scarlet fever and diphtheria), postmortem portraiture was part of a complex set of rituals developed around death. As Pat Jalland has argued, the moment of death was vitally important to Christians in the 
nineteenth century, whether they were Catholic or Protestant. In the ideal Christian death the dying person had both the time and presence of mind 'to beg forgiveness for past sins and to prove his worthiness for salvation'.7 The last utterances of a dying person, written or spoken, were therefore highly valued as evidence of his or her readiness for divine judgement. Similarly, the final expression of the dying person was closely studied. The smile of death, which can be seen in photographs as well as death masks, was regarded as proof that 'the soul had sighted the glory of heaven-it was interpreted as a sign of salvation' and provided solace to those left behind. ${ }^{8}$

Victorians displayed their portraits of the deceased within a domestic context, at home where they could be seen by family members and intimates. But there was another group of nineteenth-century Australian post-mortem portraits that was not produced for personal reasons; their context was commercial and very public. They were of bushrangers, such as Daniel 'Mad Dan' Morgan, who was photographed after his death from gunshot wounds in Wangaratta, Victoria, in $1865 .{ }^{9}$

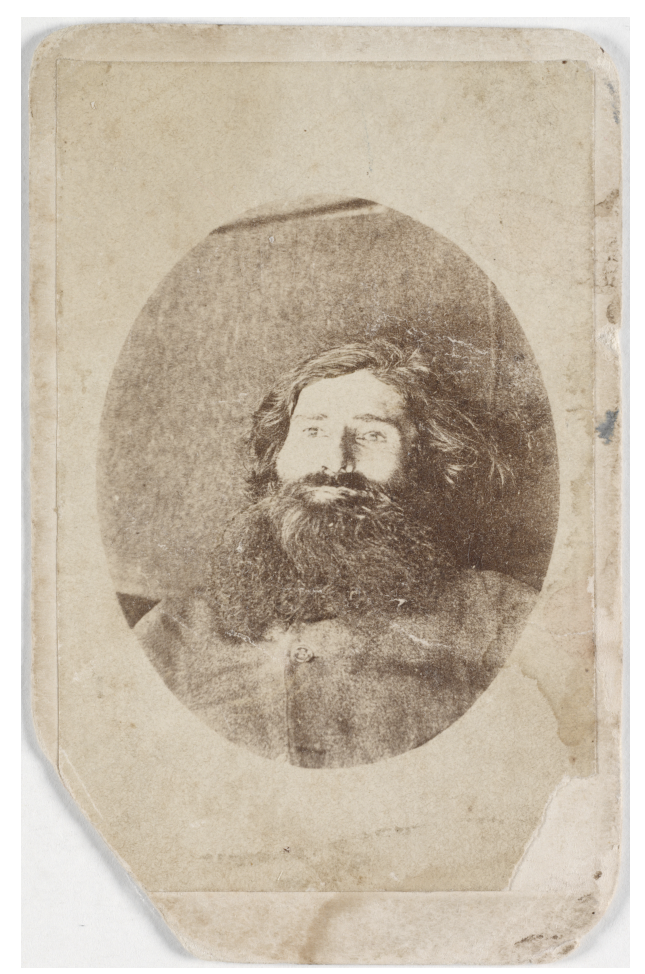

Henry Pohl, [Post-mortem photograph of Daniel ('Mad Dog') Morgan, New South Wales bushranger], 9 April 1865, carte de visite; $9 \times 5.8 \mathrm{~cm}$, on mount $10.3 \times 6.5 \mathrm{~cm}$ (Source: Mitchell Library, State Library of NSW, Call number: P1/1194) 
Henry Pohl's photograph of Morgan was produced in multiples in the form of cartes-de-visite that were common at the time; low cost ensured their circulation to a wide audience. In the representations of dead bushrangers the concern was not with the 'good death' that religious Victorians aspired to but the flipside-sudden death that allowed no time for spiritual reckoning. If a person had not prepared for death, it was believed eternal damnation would be the result. Pohl's portrait of Morgan is purposefully unsettling: the deceased bushranger's eyes are wide open (they were propped open with matchsticks), implying that he will never rest in peace.

Despite growing evidence it is still difficult to establish the full extent of post-mortem portraiture undertaken in Australia during the nineteenth century. There are a number of reasons for this. The great majority of photographs were probably kept within families and may have been destroyed once the direct connection to the subject had passed and/or changes in attitude rendered visual representations of death 'morbid', or they are still held by families and will slowly trickle into the public arena in the future. Furthermore, in Australia the market for such historical material remains relatively weak-unlike the United States, where private collectors have been active for decades and have displayed a keen appetite for unusual material. While more post-mortem portraits are coming to light as interest in the subject grows, the final number is likely to be only a very small fraction of the total produced.

It is also important to note that in colonial and Victorian periods a portrait of the deceased may have been the only photograph ever taken of them. Photography was held securely in the domain of either the professional or the well-to-do amateur and it was not until the early twentieth century that it was democratised, when inexpensive and easy to use cameras were introduced following the success of the Kodak box Brownie. From then on, portraiture became streamed into two categories: formal studio portraits associated with rites of passage, such as weddings and births, and informal snapshot photography that dealt mainly with aspects of familial life. In other words, vernacular photography did not emerge fully fledged until around the time of World War II (1914-1918).

Whether non-professional or vernacular photography from the early twentieth century included representations of the dying and dead has not been established, but it seems unlikely that it did. A number of factors would have 
militated against the practice. The first was the emergence of 'a new type of dying': what French historian Philippe Ariès has defined as 'modern death', characterised by the technological and medical control of the dying process. ${ }^{10}$ In contrast to earlier periods, the terminally ill were treated in hospital rather than at home and their dying was managed by professional 'strangers' rather than members of their own family or local community. This would have affected access to those who were dying and opportunities for photographing them. The second was the change in cultural attitudes to dying and death. The complex rituals around dying and death developed by the Victorians fell out of favour in the early twentieth century. Modern Australians had nothing to replace them with; they became increasingly removed from death and uneasy in its presence.

Another significant factor was the structure of the photographic industry and its impact on privacy. While the expanding range of lightweight $35 \mathrm{~mm}$ and instamatic cameras from the 1930s onwards made vernacular photography possible, negatives and prints were processed commercially. This meant that images of the deceased were exposed to other eyes and scrutiny, and to potential negative comment. For anyone with access to a darkroom, especially at home, the situation was obviously different and full control could be exerted over the production of imagery. It is therefore plausible that, assuming the desire for photographs of the dying and dead persisted, small numbers of post-mortem photographs might have been produced in privately run darkrooms. I have not yet been shown any examples and cannot know whether any do exist.

It seems that the practice of post-mortem portraits continued in society more broadly, but on a limited scale. Sydney photographer Sam Hood and his Dalny Studios took photographs for funeral directors Charles Kinsela and Joseph Medcalf that are now in the collection of the State Library of New South Wales. Hood's work for Kinsela's funeral parlour included a sequence poignantly titled 'Family tragedy, 1940 ', in which a female member of the Bruton family is photographed in her coffin. She is depicted on her own in one image and at the centre of a family group in another. Photographic historian and curator Alan Davies has noted that the recording of funerals was one of the more unusual contracts secured by Dalny Studios. The work undertaken for Medcalf includes three photographs of an 


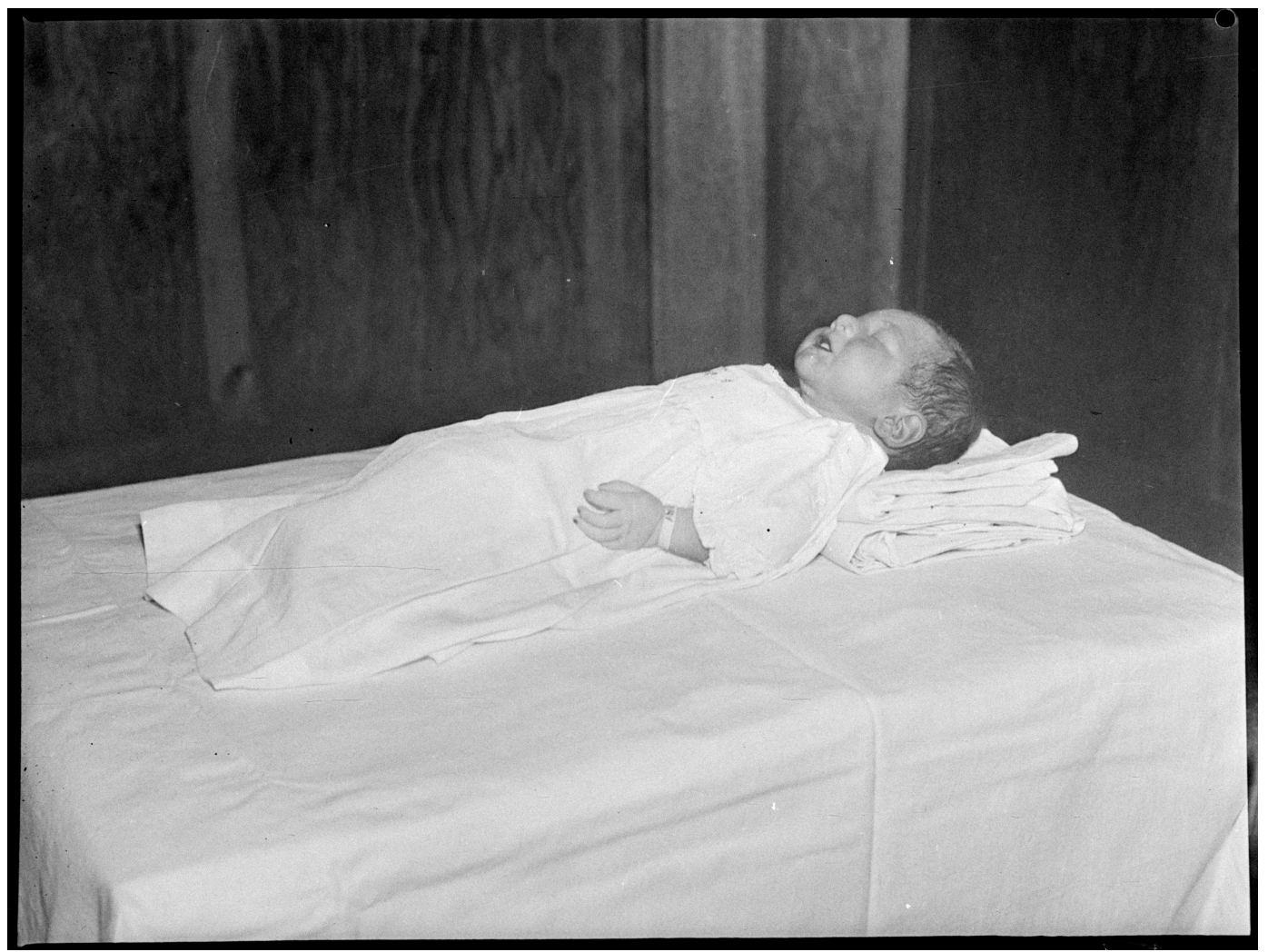

Sam Hood, Dead baby (taken for Medcalf), film photonegative (copied from original nitrate photonegative); $35 \mathrm{~mm}$

(Source: Mitchell Library, State Library of NSW Call number, Home and Away - 24825)

unidentified baby that differ markedly from nineteenth-century post-mortem portraits like those in the Holtermann collection. The effect is far less personal, due to the austere environment in which the baby was photographed and the lack of any softening devices, such as the flowers included in earlier works.

It was not until the 1980s that photographs of the dying and dead reemerged on a more substantial level, for a raft of reasons. Of these, it is important to note the challenges to the dehumanising and alienating aspects of modern death mounted by psychologists, sociologists and psychiatrists from the late 1960s onwards. These were signalled by the publication of Swiss-American psychiatrist $\mathrm{Dr}$ Elisabeth Kübler-Ross's groundbreaking book On Death and Dying in 1969.11 Also crucial was the hospice movement, established in Britain in the late 1960s by Dame Cicely Saunders, which transformed the treatment of the terminally ill. Saunders advocated integrated or total care which addressed the physical, psychological, 
social and spiritual needs of the patient; this multi-disciplinary approach formed the basis of the palliative care movement in Australia and the eventual establishment of hospices in the late 1980s. But perhaps the most significant event was the HIV/AIDS epidemic. By the early 1990s, over 17,700 cases of HIV infection had been documented in Australia and more than three thousand mostly young people had died from AIDS-related illnesses (by 2005 the total number of deaths was 6,594). ${ }^{12}$ Dealing with dying and death suddenly became an inescapable and overwhelming reality, triggering a variety of creative responses. In the late 1980s, gay men and women began to create their own rituals around dying, death and grief that better suited the realities of the situation they confronted. They planned their own funerals, organised their own wakes and designed their own panels for the AIDS quilt. Photographer William Yang was one of those who assumed a public and

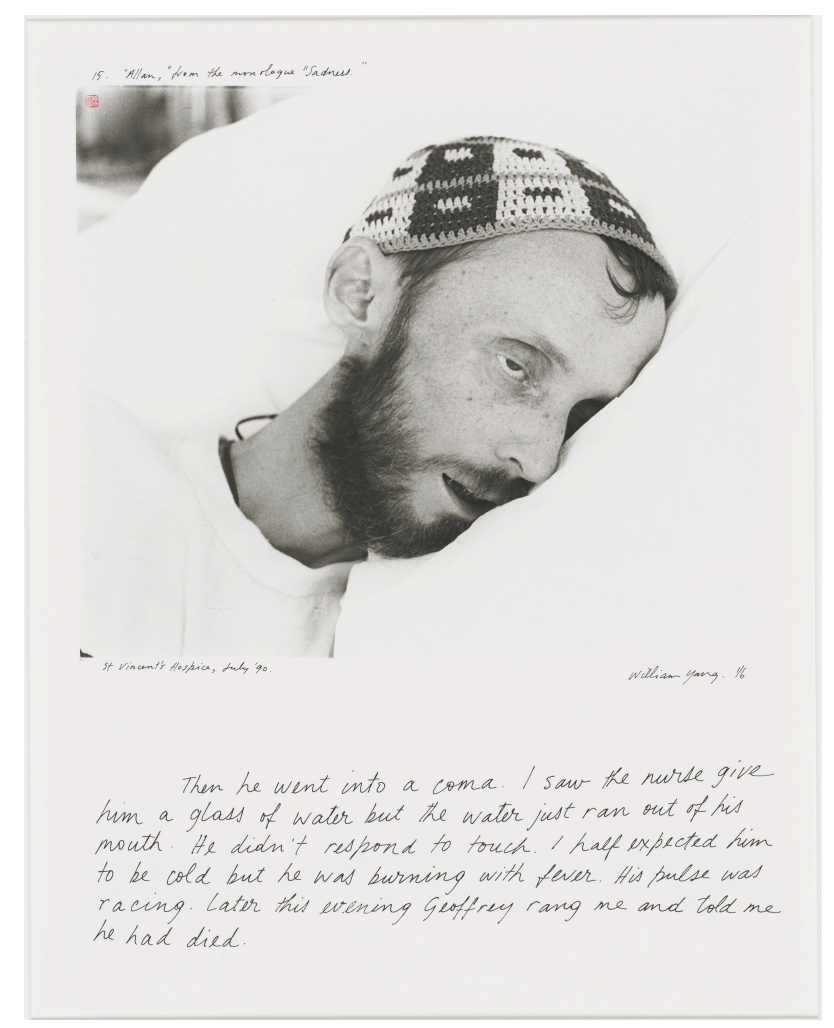

William Yang, 'Allan' from the monologue 'Sadness', 1980, 1988-90 [photographs and monologue chronicling the death from AIDS of Allan Booth] Image no.18: St Vincents Hospice, Darlinghurst, July 1990 , silver gelatin print; $50.5 \times 40.5 \mathrm{~cm}$

Source: Mitchell Library, State Library of NSW Call number: PXD 745 
political role, exhibiting his well-known series of photographs of his friend Allan and performing his monologue, Sadness. Yang's work was vitally important in its nuanced and dignified engagement with dying and death; combining black-andwhite documentary photographs of his friends with his own personal, hand-written narrative.

Another crucial development in the late 1980s related to neonatal death. Here vernacular photography-by medical staff untrained in photography-came into its own. In the last two decades it has been common practice for nurses to encourage grieving families to photograph their baby, or for them to take photographs of the baby on the family's behalf. The conventions deployed are well established: the baby is usually pictured with her mother and father separately and together, as well as with other members of her family. The baby is shown being bathed, being dressed and with toys; details of her hands or feet are also common. The photographs, originally in the form of colour snapshots, are part of a larger collection of memorial objects that might include hand and foot prints, an identity bracelet, perhaps a of lock of hair and a toy. At Canberra Hospital these objects are assembled in what is described as a 'memory box' and given to the baby's parents (if the parents do not wish to take it at the time it is kept at the hospital for them).

Photography played a key role in bringing neonatal death into public consciousness when Vanessa Gorman's controversial documentary Losing Layla was screened on ABC TV's Australian Story in 2001. It dealt with the tragic death of Gorman's daughter, Layla, eight hours after childbirth and was followed up with a book Layla's Story: A Memoir of Sex, Love, Loss and Longing. Both the documentary and the book included images of Layla taken after her death taken by Gorman's sister, Alex, an obstetrics social worker. ${ }^{13}$ These photographs, which are in the public domain, display the hallmarks of others which I have seen.

The photographs of babies mark a critical juncture in the representations of the dying and dead. They belong to the vernacular uses of the photographic medium, not to the field of professional photography that had governed post-mortem photography in the nineteenth century. But they pre-date the digital revolution, which has greatly expanded the possibilities for vernacular photographs dealing with mortality. The neonatal images also signal a juncture of a different sort, for the next section of my essay is concerned with a totally contemporary realm. It relates 
directly to lived experience, and the information is drawn from accounts people have given me and photographs they have shown me in the last five years.

What are the vernacular digital photographs of which I speak? First it should be said that they are drawn from a limited circle, comprising only those that I have seen myself but which I assume are not untypical. They do not form a unified body; there is no school or group of post-mortem portraiture as such and the photographs are made with very little knowledge about earlier practices in Australia (though that is likely to change as historical material becomes more widely known). Those taking vernacular photographs of the dying and dead are generally acting on their own impulses, often in isolation and without the knowledge or permission of others. Sometimes the photographs are secret, their existence known by only one or two people. The deaths depicted are of a particular kind-what might be described as a 'natural death' from illness or old age rather than a sudden death resulting from an accident or act of violence. In other words, an intact body, with no visible signs of trauma, is likely to be considered most suitable for photography by the deceased's intimates. The images are taken either on digital cameras or mobile phones and are either still photographs, short video clips or both.

A number of common features are apparent in the photographs I have been shown. Most striking is their modesty. They do not exhibit the heroics and universalising of experience common to art photography, as in W. Eugene Smith's deathbed scene from his Spanish Village series (1951). Instead the emphasis is on specifics, and details are both abundant and prosaic. Also noteworthy is the variety of settings, which include home, hospital, hospice and occasionally, if there has been a viewing of the body, the funeral parlour. The level of formality in the photographs varies in accordance with the stage in the dying process. Those taken after death are the most carefully composed, assuming an almost ceremonial status as the last photograph of the loved one. They also differ from their nineteenth-century counterparts in the use of different vantage points, especially close-up, to picture the face. Such intimate representations are testament to the personal connection between the photographer and deceased, which is also borne out in the choice to photograph fragments and details, as well as accessories such as soft toys that have obvious personal significance. 
The proliferation of death-related vernacular photography does, of course, have a wider context in the development of less repressive, more liberal approaches to dying and death that can be seen across many sectors of society. It is part of an ongoing reaction to the medical and technological event dying has become, another way of taking control of one's own circumstances (evident, for example, in the popularity of personalised funerals and choice of favourite songs to be played at the service). Photography provides a means of reclaiming the deceased from their position as a patient, rehumanising them and reasserting their individuality. A grandmother's hands are photographed; she holds carefully arranged rosary beads that will be cremated with her. All this is part of a rich array of personal gestures, of acts of love and affection that are now more commonly extended to the deceased through the direct involvement of the bereaved: choosing clothes for the corpse, combing their hair, making things for them, writing a note and placing it in the pocket of their clothes. Taking photographs in this in-between time, after death but before the body is given up to the experts, is also linked to the last possible embodied interactions. After her mother died, a woman told me:

I climbed onto the bed beside her while she was still warm and stayed with her as long as I could. I felt compelled to take some photos before she was taken away. I just wanted to photograph her while she was still there. ${ }^{14}$

Other factors influencing vernacular digital photographs of death relate more specifically to photographic practice of the past and present. They are indicative of the medium's expanded reach into every stage of the life cycle, from the birth of a baby on one hand (the first photographs of a baby are now prefigured by ultrasound images of the foetus) to the death of an individual. They also return the photographic medium to its ontological roots and attest to the persistence of its realist traditions-this in the digital era when it was initially, and erroneously, assumed that photography's demise was imminent. It seems that the desire for an accurate likeness, for authenticity, for a portrait in its most conventional 'truthful' form, has not diminished. These new photographs also have a common bond with their Victorian predecessors through their location in the domestic sphere, encompassing family, friends and home. 
The recent photographs of which I write are not simply vernacular. Crucially, they are digital, the product of the most up-to-date technologies. As such, they are underpinned by one simple but hugely important fact. Digital technologies enable non-professional photographers to bypass the involvement of others in the processing and printing of their images. This allows an unrivalled level of control and privacy over what is produced, foreshadowed only by the Polaroid process introduced in the 1970s and the efforts of amateur photographers to make their own negatives and prints.

The ease of digital photography and its adaptability to different lighting conditions engenders a high degree of spontaneity. The mobile phone takes this even further as it is no longer even necessary to plan ahead, to bring one's camera. Three times I have been told that a family member had no intention of photographing their loved one after death, but did so spontaneously once they realised they had their mobile phone on them, a phone with a camera. With digital cameras, as opposed to those using film, a huge number of photographs can be taken, far more seamlessly. This potential for multiplicity is also unprecedented; I have been shown thirteen hundred still photographs and short video clips of a dying subject that were taken over a two-week period.

The ways vernacular digital photographs are used depends on the circumstances in which they were made-whether their existence is known by others and tolerated or appreciated by them. Responses vary hugely, from complete secrecy for fear of a hostile reaction from other family members, to full disclosure (a course of action that can have unpredictable results, shocking and alienating some and causing considerable distress). Sometimes the images never assume material form as prints or 'hard copy'; they exist only as jpegs and are viewed, if it at all, via the screen. In other cases, they are printed and made visible within a tightly circumscribed environment such as the home, where, for example, a photograph of a stillborn baby might be framed and hung on a bedroom wall). Once I was shown a keychain that incorporated a tiny portrait of a stillborn baby; having been kept in her father's trouser pocket, as close to his body as possible, it was warm when passed to me.

New technologies offer not only new possibilities for the production of images but for their dissemination as well. The family of Monique Van Nieuwland 
relied on email to 'communicate events around the death of a family member, between Australia and Holland'.15 Monique has lived in Canberra for many years whereas most of her large family still lives in Holland. When her much-loved elderly aunt became ill, Monique keenly felt her separation from her family and was in constant email communication with them. Her sister sent her regular updates on her aunt's condition as well as photographs taken in the days leading up to her death. They form a narrative that begins with a portrait of Monique's aunt at her nursing home and a close-up of a page from a book in the nursing home's chapel in which the aunt had written: 'I can no longer go on'. The photographs that follow show the aunt on her death bed, shortly after her death when her body had been washed and dressed by family members, and in her coffin. The narrative concludes with the funeral service and a photograph of the cemetery in which the urn containing the aunt's ashes is displayed alongside her parents' grave in the town where she was born.

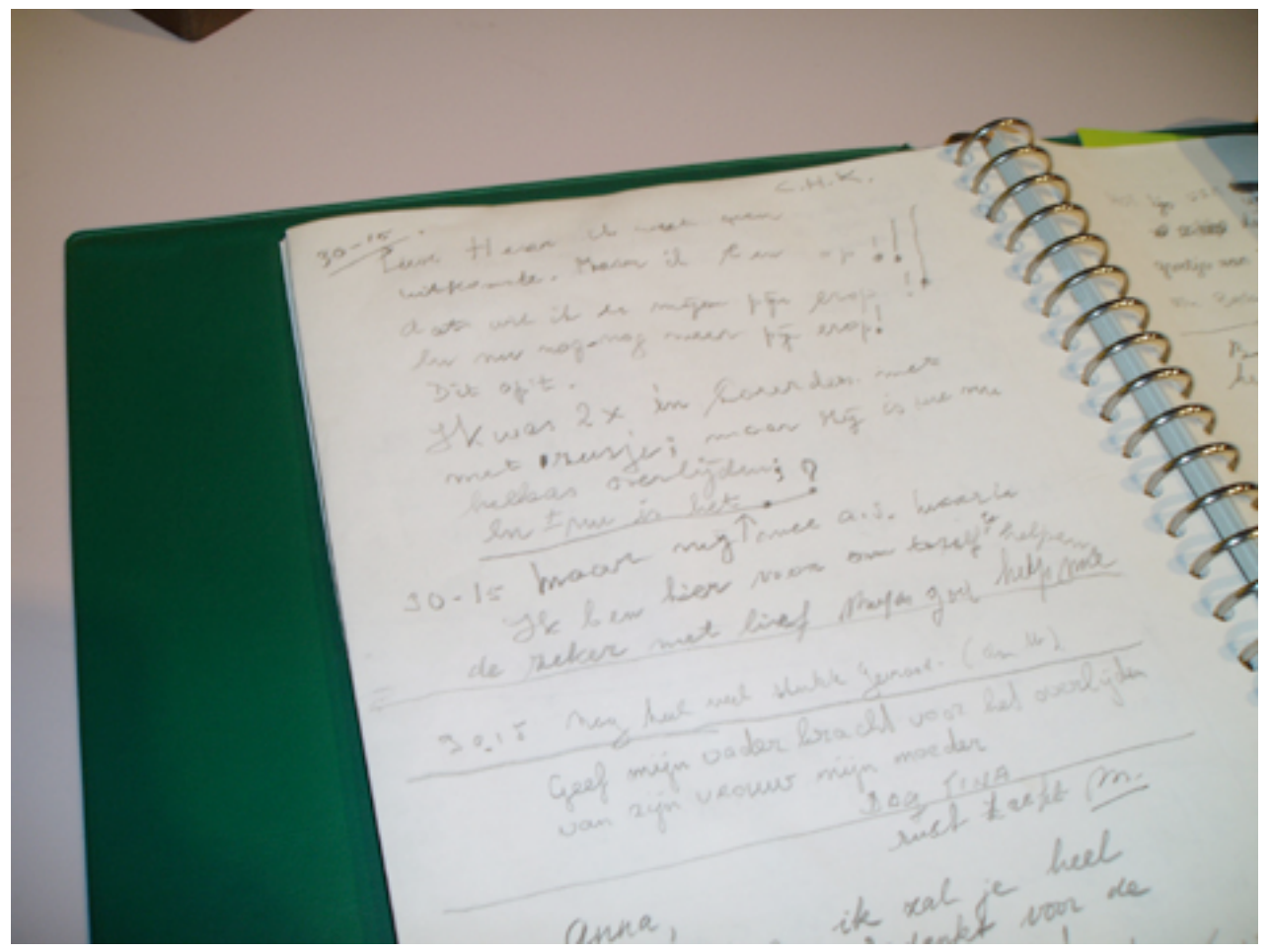

Bernadette van Vugt, Book in nursing home chapel with Tante Tineke's entry saying 'I can no longer go on', digital photograph, 2007

(Source: courtesy of Monique Van Nieuwland) 


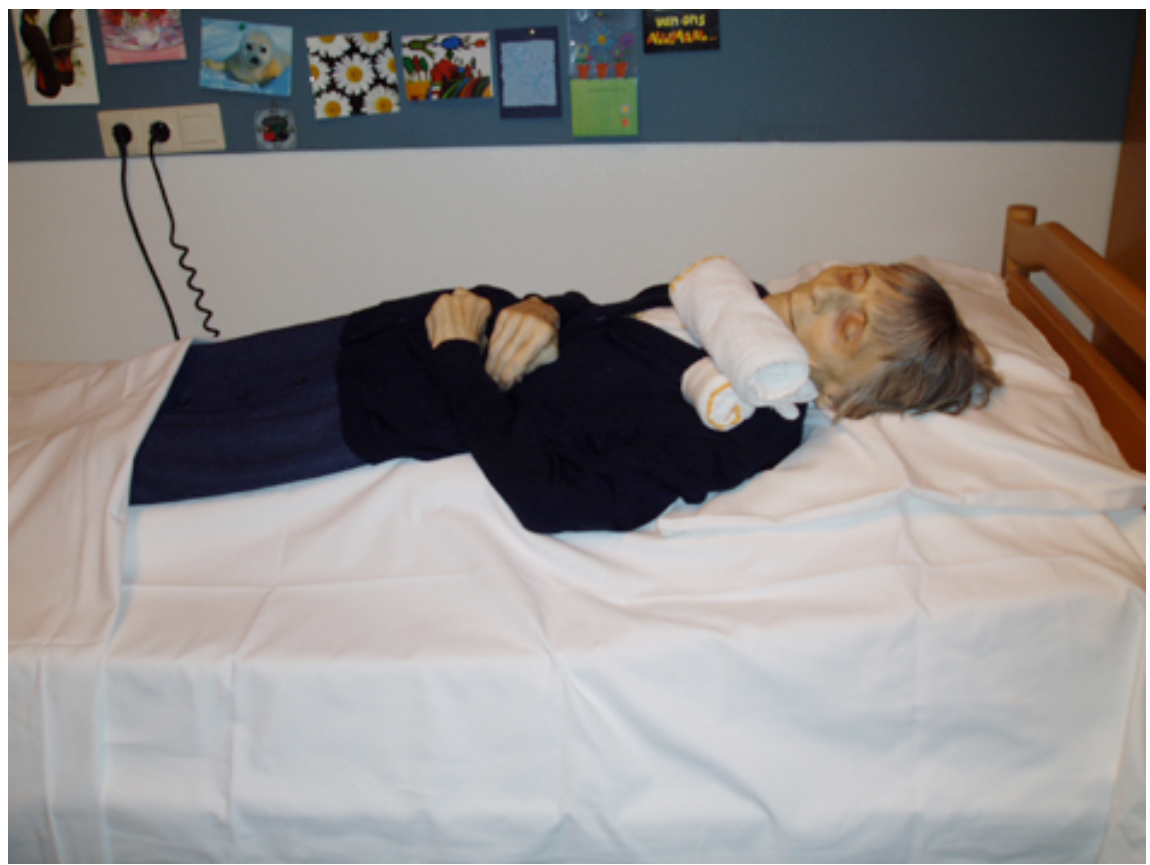

Bernadette van Vugt, Tante Tineke's body after being washed and dressed by family members, digital photograph, 2007

(Source: courtesy of Monique Van Nieuwland)

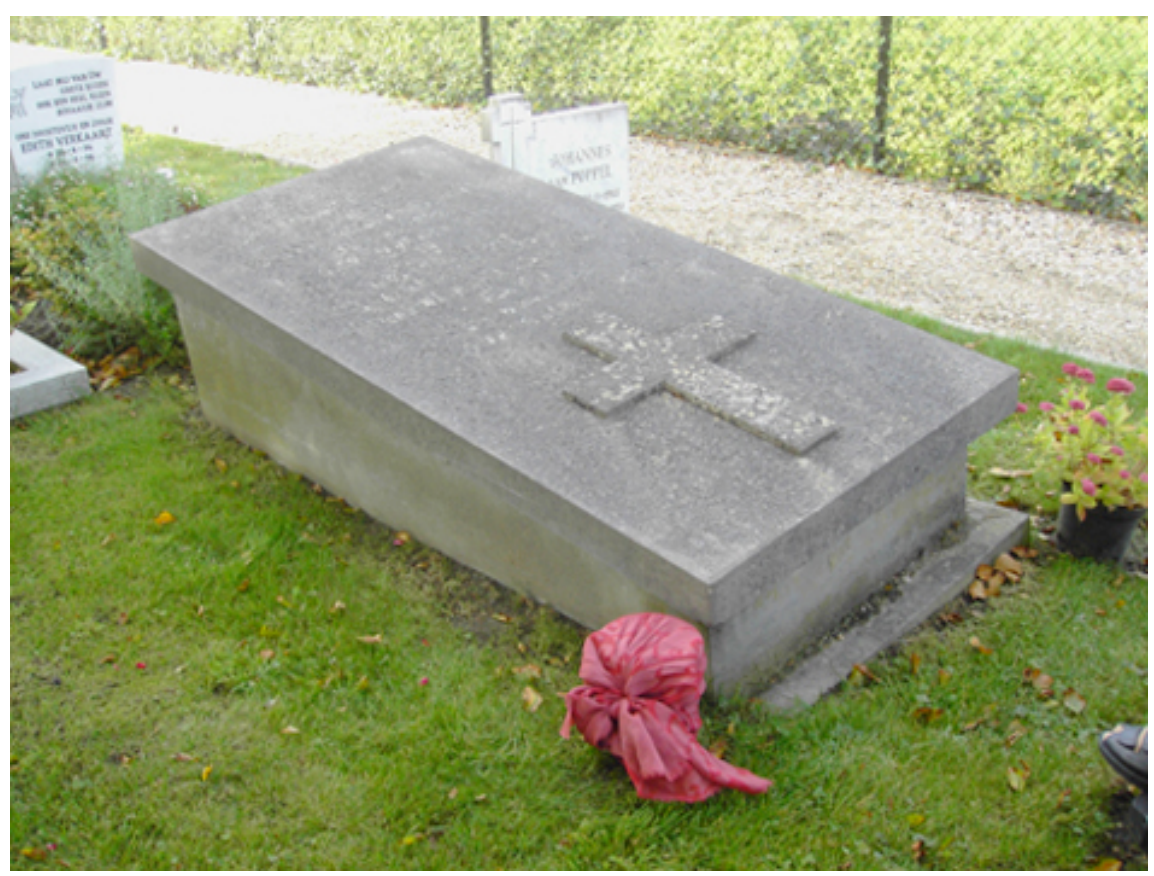

Monique Van Nieuwland, Tante Tineke's ashes in (wrapped) urn at her parents' grave in her town of birth, digital photograph, 2007 
For Monique Van Nieuwland, the photographs were a source of comfort because there was very little delay between the time they were taken and her viewing of them. The connection to real time meant that although Monique could not be with her siblings who were taking turns at her aunt's bedside, she felt she was part of the event, keeping watch on the other side of the world. Monique also used the photographs to reinforce social and familial bonds, showing them to her own children so that they were aware of what was happening to their great aunt in Holland. Such a process would now be even easier and more direct with webcam.

I have been arguing that digital technologies have made it possible for images of dying and death to be produced more readily and in greater privacy than ever before. Concurrent with this development is a seemingly contradictory phenomenon-the appearance of contemporary vernacular images of the dead in public spaces. One example of this can be seen in the program for a funeral service for an elderly woman held in Sydney in 2006, in which two photographs were reproduced. The cover image depicted the deceased as a young woman while the image on the back of the program was taken after her death. The first image is a relatively formal studio portrait whereas the second is an informal digital photograph in which she is shown in close-up, one hand around a teddy bear lying on the pillow beside her. Juxtaposing the two images of the once living and now dead subject serves to emphasise that her personal journey has ended without abstracting the experience. The emphasis remains on individual and specific qualities with no larger or universal claims being made.

My second example involves a new way of using photography in a memorial. While roadside and other memorials frequently incorporate photographs of living subjects, an informal memorial recently built in the nature park near our Canberra home departed from convention by displaying a post-mortem photograph. The site had been carefully chosen: on the side of a hill and under a tree which offered some shelter. The memorial took the form of a circular enclosure built from rock and tree limbs, inside which a small garden had been planted, a series of candles laid out and a large wooden cross erected. Adorning the timber fence were personal items including a teddy bear and a framed close-up photograph of a tiny baby's hands. The full memorial existed for only a few weeks, after which the timber construction with the cross was all that remained. Each of the personal items, including the 


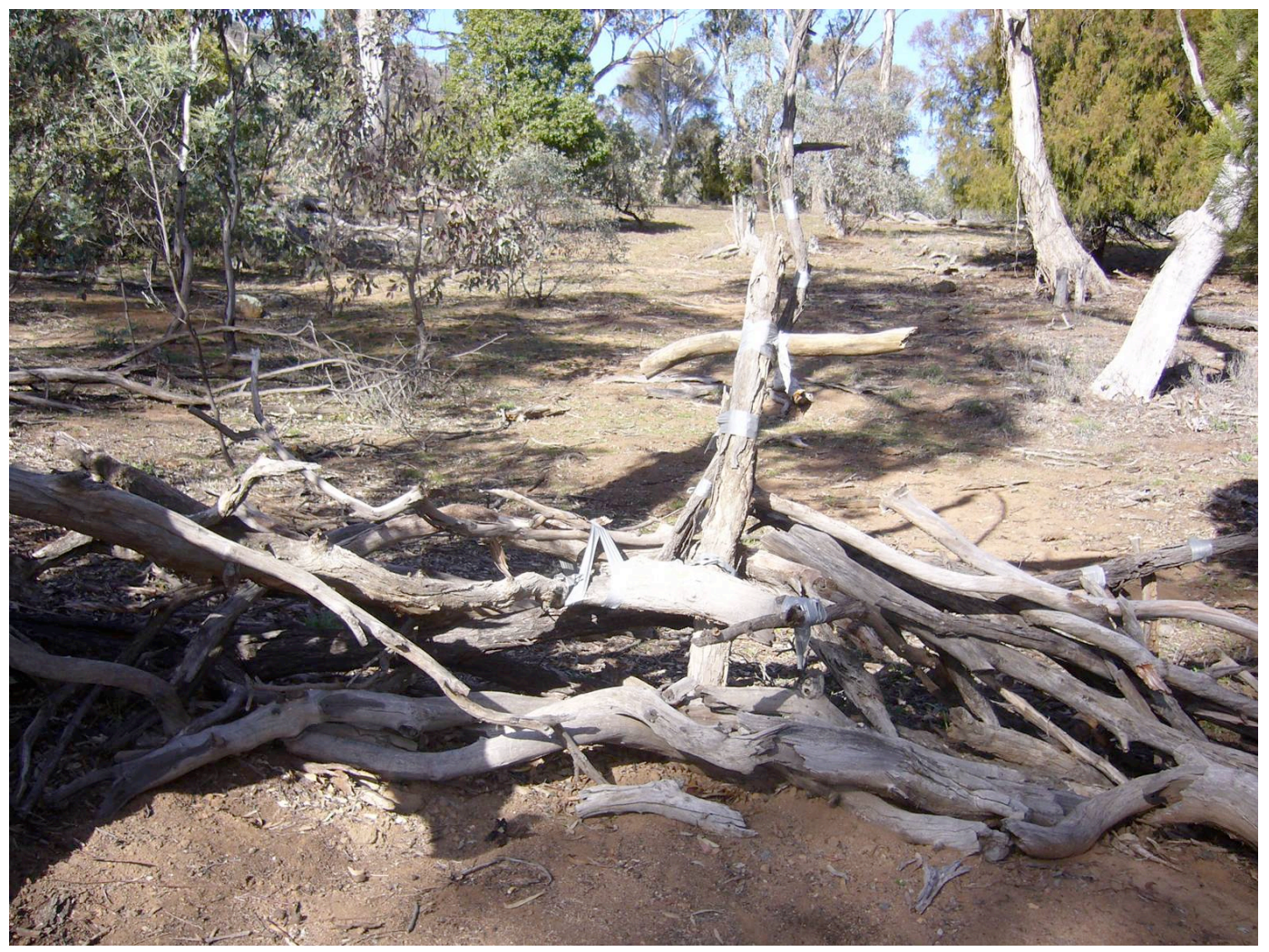

Helen Ennis, View of an informal memorial to a stillborn baby boy, Mt Ainslie, ACT, digital photograph, 2009

photograph, has gone. For me, encountering an intensely private image of a stillborn baby in a public space was a poignant and disorienting experience.

In relation to the affective power of such photographs Roland Barthes made a useful distinction between those that are 'unary' and those that cause a 'disturbance'. In Camera Lucida he describes those that can be instantly understood as 'unary'. In his words: 'The photograph is unary when it emphatically transforms "reality" without doubling it, without making it vacillate: no duality, no indirection, no disturbance.'16 The photographs I have been seeing are different, they belong to another category, to those photographs that for whatever reason cause a 'disturbance'. Barthes reflected that:

The photograph touches me if I withdraw it from its usual blah-blah: 'Technique', 'Reality', 'Reportage', 'Art', etc.: to say nothing, to shut my eyes to allow the detail to rise of its own accord into affective consciousness. ${ }^{17}$ 
This essay has considered some of the changing visual conventions and uses of Australian post-mortem photographs from the nineteenth century to the present. On the basis of photographs I have been shown in recent years I have argued that digital technologies are being used to extend the possibilities of visual representation and to help express changing attitudes to dying and death. But they appear to offer even more than that-a more intimate engagement with dying, death and grieving than was ever possible with photography before. Not long ago, I received an email in which a recently bereaved daughter explained that she could not photograph her mother during the last weeks of her life. Her mother was 'private' and would not have wanted her daughter 'photographing her declining frailty'. As part of a wordless process the daughter responded by recognising that 'now was just time for me to be', to be in the moment and, more significantly, to be in the moment with her mother. She continued:

My camera stayed at home mostly, or in the bottom of my bag. On the morning of my mother's death I went in with the girls, we said our final goodbyes and I took one photograph with the handbag digital for the girls, and we went home to be with grandpa. 18

As I see it, digital vernacular photographs dealing with the deaths of loved ones are likely to become more common, but this is not to say that they will become more visible. Indeed, the lack of materiality of a digital photograph may prove to be a major attraction, displacing the long held practice of creating photographic objects-that is, prints. Digital technologies offer a new, immaterial realm with expanded options not only for privacy, but secrecy as well.

Helen Ennis is an independent photography curator and writer. Her recent publications include Reveries: Photography and Mortality (2007) and Photography and Australia (2007). Helen was formerly Curator of Photography, National Gallery of Australia and is currently an associate professor at the ANU School of Art. 
-NOTES

${ }^{1}$ Chris Townsend, Art and Death, I.B. Tauris, London, 2006, p. 4.

2 Helen Ennis, Reveries: Photography and Mortality, National Portrait Gallery of Australia, Canberra, 2007. The exhibition opened at the National Portrait Gallery in April 2007 and toured to Queensland University Art Museum and Mornington Peninsula Regional Gallery in 2007-08.

3 Jay Ruby, Secure the Shadow: Death and Photography in America, MIT Press, Cambridge, Mass., 1995. See also Stanley B. Burns, Sleeping Beauty: Memorial Photography in America, Twelvetrees Press, Altadena, 1990.

${ }^{4}$ Shelley Clarke cites Gael Newton's view that post-mortem portraiture was not common in Australia in Forgotten Memories: Post-mortem Photographic Portraiture in Australia before 1920, MA thesis, Australian National University, 2004.

5 See such search categories as 'cadavers, human' or 'funeral'.

6 The advertisement appeared in the Illustrated Melbourne News, 16 January 1858, p. 38; 23 January 1858, p. 50; 30 January 1858, p. 60; 6 February 1858, p. 67. See Diane Reilly and Jennifer Carew, Sun Pictures of Victoria: The Fauchery-Daintree Collection, 1858, Currey O'Neil Ross, Melbourne, 1983, p. 16. No post-mortem portraits by Fauchery have yet been identified.

7 Pat Jalland, Death in the Victorian Family, Oxford University Press, New York, 1996, p. 26.

8 Jalland, p. 37.

9 See Helen Ennis, 'Portraiture in Extremis' in Daniel Palmer (ed.), Photogenic:

Essays/Photography/CCP 2000-2004, Centre for Contemporary Photography, Melbourne, 2005, pp. 2340, and Ennis, Reveries.

10 Philippe Ariès, The Hour of Our Death, A.A. Knopf, New York, 1981.

11 Elisabeth Kubler Ross, On Death and Dying, Macmillan, New York, 1969.

12 See Ted Gott, 'Agony Down Under: Australian Artists Addressing AIDS' in his Don't Leave Me This Way: Art in the Age of AIDS, National Gallery of Australia, Canberra, 1994, p. 1.

13 Vanessa Gorman, Layla's Story, Viking, Melbourne, 2005.

14 Personal correspondence with the author, 2009.

15 Personal correspondence with the author, 2007.

16 Roland Barthes, Camera Lucida, Jonathan Cape, London, 1980, p. 41.

17 Barthes, p. 42.

18 Lisa Coleman in an email to the author, 2010. 